\title{
Periodistas sin identidad profesional: puntualizaciones al proyecto para un futuro Estatuto
}

\author{
Dra. Elena Real Rodríguez \\ Profesora de Ética y Deontología de la Información \\ Dpto. Periodismo III - Facultad de Ciencias de la Información \\ Universidad Complutense de Madrid \\ ereal@ccinf.ucm.es
}

\section{Resumen}

Los proyectos de la FAPE y del FOP (actualmente en tramitación parlamentaria) sobre un futuro Estatuto del Periodista, constituyen un peligroso obstáculo en el largo y costoso camino que debe recorrer el Periodismo desde el oficio hasta la profesión. Este artículo pretende desenmascarar los engaños y trampas que encierran, así como reivindicar las legítimas aspiraciones del Periodismo-profesión.

\begin{abstract}
The FAPE and FOP proyects (at the moment in parliamentary procedures) about a future Journalistic Statute, constitute a dangerous obstacle in the long and hard way that Journalism must go through from the job to the profession. This article tries to unmask the deceits and traps that they lock up, as well as to claim the legitimate aspirations of Journalism-profession.
\end{abstract}

Palabras clave: Periodismo, Profesión periodística, Estatuto profesional

Key words: Journalism, Journalistic profession, Professional Statute

$E$

n noviembre de 2004, el Pleno del Congreso de los Diputados aprobó la toma en consideración de una Proposición de Ley del Estatuto del periodista profesional, cuyo texto es idéntico al promovido por el Foro de Organizaciones de Periodistas (FOP) en $2001^{1}$. A lo largo de este curso parlamentario será debatida y, si prospera su tramitación, se convertirá en ley orgánica. ${ }^{2}$

\footnotetext{
${ }^{1}$ Entonces conformado por la Federación de Asociaciones de la Prensa de España (FAPE), el Sindicato de Periodistas de Cataluña, el Colegio de Periodistas de Cataluña y las Agrupaciones de Periodistas de CCOO y UGT. A día de hoy, la FAPE se ha desvinculado de este organismo precisamente por discrepancias en el tema del Estatuto Profesional, y se han incorporado el Colegio de Periodistas de Galicia y la Federación Española de Sindicatos de Periodistas (a la que ha dejado su sitio el sindicato catalán). El texto fue refrendado un año después por la III Convención de periodistas de España.

${ }^{2}$ La consulta de este documento puede efectuarse en la siguiente dirección electrónica: www.xornalistas.com/pdf/PLEPP.pdf
} 
Vaya por delante la necesidad de configurar un nuevo Estatuto Profesional que sustituya al promulgado en 1967, emanando de la Ley de Prensa de 1966 y modificado en 1976, que mantiene todavía parte de su vigencia, ya que como bien señala Carlos Soria "ambas disposiciones legales no han sido derogadas expresamente en su totalidad por una ley posterior: sólo se ha producido, a través de leyes, derogaciones parciales de artículos o capítulos completos de la Ley de Prensa. Tampoco la Ley de Prensa en su conjunto ni la legislación que ella impera -por ejemplo, el Estatuto de la Profesión Periodística de 1967- han sido derogadas en su conjunto, repito, por la Constitución de 1978. La Constitución no ha derogado implícitamente toda la Ley de Prensa de 1966; lo que la Constitución ha podido producir es la derogación tácita de normas contenidas en la Ley de Prensa que resultan incompatibles con normas contenidas en la Constitución, sean o no estas normas de aplicación directa". ${ }^{3}$ Conviene recordar, a diferencia de lo que opinan otros estudiosos del derecho, que la mera ignorancia o la nula aplicación de una normativa no es un procedimiento jurídico que proceda a su cancelación. ${ }^{4}$ Por lo que no se debe mantener por más tiempo esta incertidumbre jurídica. Sin embargo, esta urgencia que se prolonga ya cerca de treinta años no puede ser resuelta de modo tan nefasto para las legítimas aspiraciones de constituir una verdadera profesión periodística.

El proyecto de Estatuto se burla del genuino concepto de periodista, ignora en qué consiste el Periodismo y diseña un peculiar modelo profesional cuya "originalidad" reside en consagrar el Periodismo-actividad (propio del oficio) maquillándolo con tintes de profesionalidad, pero desvirtuando aquellos rasgos que pudieran tomar de las auténticas profesiones. Tampoco es muy tranquilizador el texto alternativo aprobado por la Federación de Asociaciones de la Prensa de España (FAPE) en mayo de 2005. ${ }^{5}$ Apremia, pues, establecer una serie de puntualizaciones que desenmascaren de una vez por todas las falacias y demás supercherías que se ciernen sobre la actividad periodística, y que el proyecto de Estatuto pendiente de tramitación parlamentaria pretende instaurar con marca indeleble.

\section{RASGOS DISTINTIVOS DEL CONCEPTO "PROFESIÓN"}

Existe hoy por todas partes una tendencia generalizada hacia la profesionalización. Todos se consideran profesionales (arquitectos, abogados, médicos, enfermeros, bomberos, confiteros, artistas, deportistas, ferroviarios, escritores, sastres, panaderos, notarios...), y elevan la actividad o empleo que desempeñan al ya poco selecto catálogo de profesiones. En sentido amplio, cierto es, esta adulteración del

\footnotetext{
3 SORIA, Carlos: "Los restos del naufragio", en Periodistas, no 35, julio 1990, p. 12.

${ }^{4}$ Es más, el Tribunal Supremo ha declarado la vigencia parcial de la Ley de Prensa y del Estatuto de 1976 en distintas sentencias, que consideran sólo puntos concretos. Es decir, declara anulados ciertos artículos de ambas normativas, pero acepta implícitamente la vigencia de otras cuestiones.

${ }^{5}$ Publicado en el número 2 de la revista Periodistas que edita la FAPE.
} 
término profesión permite que todo trabajo o actividad ocupacional -aún sin reunir los requisitos propios de aquélla- pueda ser considerado como tal. Basta preferentemente con ejercer dicha actividad y percibir por ello una retribución que constituya el principal medio de vida. De este modo, no es de extrañar que quien cumpla con tal atribución se tenga por profesional y a la ocupación que lleva a cabo como profesión. Pero la noción de profesión no debe caer en esta confusión. Al menos así han tratado de hacerlo ver filósofos, sociólogos y estudiosos de la ética profesional, que han puesto un loable empeño en señalarnos las diferencias. Toda profesión es sin lugar a dudas un trabajo, pero no todos los trabajos pueden ser distinguidos con el cariz y rango de las profesiones. Aunque ocupen, digámoslo así, peldaños diferentes, tampoco debemos colocarlos en compartimentos estancos. Pues, de algún modo, existe entre ambos lo que podríamos denominar un vaso comunicante que funciona básicamente en sentido ascendente. Es decir, oficios y empleos que en su día no podían ser calificados de profesiones evolucionaron, empujados por la exigencia de los ciudadanos ante la cada vez mayor trascendencia y responsabilidad de sus tareas, hasta el más prestigioso -pero al mismo tiempo exigente- nivel de las profesiones.

La conformación de una profesión empieza por tener claro en qué consiste una determinada ocupación y cuál es su misión ante la sociedad. Prosigue en el desarrollo de un cuerpo de conocimientos desconocidos para los no expertos. Bullough ve en este rasgo la clave decisiva para que una actividad pueda ser considerada o no como una profesión. ${ }^{6}$ En el siguiente paso se institucionaliza la transmisión de dichos conocimientos, con lo que se consolida el monopolio o derecho exclusivo para ejercer el quehacer en cuestión. Esto conduce, como consecuencia lógica, a la instauración de una organización válida que garantice tanto el control del acceso a la profesión como el desempeño responsable de la misma: nace así la figura del Colegio profesional, a cuya pertenencia habrán de acogerse obligatoriamente los profesionales. Para lo cual se hace necesario a su vez la elaboración de un estatuto profesional (en el que se indiquen sus correspondientes funciones, derechos y obligaciones), y del oportuno código deontológico. Todo ello se completa con una normativa laboral general y/o específica, según los casos, para el conjunto de los profesionales. Finalmente, y en común con el resto de trabajos, la profesión ha de ser una dedicación estable, principal, que constituya el primordial sustento económico como medio de vida.

\footnotetext{
${ }^{6}$ Citado por HORTAL ALONSO, Augusto: Ética general de las profesiones, Desclée De Brouwer, Bilbao, 2002, p. 49.
} 


\section{NO DEBE CONFUNDIRSE EL DERECHO A LA LIBERTAD DE EXPRESIÓN CON EL DERECHO AL EJERCICIO DE UNA PROFESIÓN}

La concepción del Periodismo como el mero uso y disfrute de un derecho humano esencial (el de la libertad de expresión y, por consiguiente, de la libertad de información) que pertenece a todos y cada uno de los ciudadanos, se ha convertido en la disculpa más recurrente para retrasar sine die su natural transición del nivel de actividad a la categoría de profesión. Ya que en virtud de semejante planteamiento no es posible establecer algún tipo de condicionante que limite el acceso a todo aquel que se muestre interesado en hacer de periodista, bien con el beneplácito del empresario de turno bien mediante las facilidades que hoy brinda Internet para publicar lo que a cada cual le apetezca, siempre y cuando disfrute de los necesarios recursos económicos -por muy asequibles que estos sean-para "colgar" contenidos en la red. Olvidan quienes de este modo piensan que el periodista no se conduce sin más como un ciudadano cualquiera en el ejercicio efectivo de este derecho universal, sino que actúa, ante todo, como un profesional al servicio de unas facultades (las de investigar y difundir de acuerdo con nuestro texto constitucional) que le han sido confiadas por el conjunto de la sociedad, dada la dificultad que el propio colectivo social tiene de poder desarrollarlas con el debido cuidado por sí mismo. Es, por tanto, la satisfacción del deber de informar (correlativo al derecho que todos disfrutamos), en la especialidad que al Periodismo le corresponde, el que identifica al periodista frente al resto de los ciudadanos sin distinción profesional, es decir, que no se comportan al igual que él consagrando su quehacer diario a las obligaciones y responsabilidades que la práctica periodística conlleva. Resulta indispensable, pues, diferenciar entre el uso y disfrute de un derecho constitucional y el derecho al ejercicio profesional de una actividad determinada. Disparidad que para algunos resulta bastante obvia, pero no así para una nada desdeñable y aparente mayoría que no parecen reparar en ella (o simplemente la menosprecian) y echan mano, una y otra vez, del argumento falaz anteriormente esgrimido para negarle al Periodismo lo que le pertenece en justicia y con toda lógica.

En contra de lo que se nos quiere hacer creer, la libertad de expresión no es en modo alguno un derecho absoluto e ilimitado por lo que habrá que atenerse, al menos, a aquellas restricciones que vengan aconsejadas por el sentido común. Los graves y perniciosos efectos que un desempeño interesado y no convenientemente cualificado del Periodismo podría acarrear a la sociedad, hacen preciso que esta actividad sea ejercida únicamente por aquellos que previamente hayan sido preparados con la imprescindible suficiencia; ya que prevalece, y esto es importante resaltarlo, el interés social de asegurar la idoneidad profesional sobre los intereses del individuo o de la empresa a elegir profesión y personal laboral, respectivamente, para evitar los daños que pudieran derivarse de la impericia. Se limita de esta manera sólo el derecho al libre ejercicio de profesión en virtud de un derecho mayor. No se menoscaba en ningún momento la libertad de expresión de la persona, que puede seguir haciendo uso de su derecho constitucional, lo que no le lleva a convertirse en periodista ni a realizar el cometido informativo que solamente éste 
debe ejecutar. Como tampoco se ve afectada la libertad de contratación de la empresa periodística que podrá emplear a quien buenamente le plazca siempre y cuando sea competente en la tarea que ha de llevar a cabo, lo que, por otro lado, redunda en su propio beneficio como empresa que, no nos olvidemos, detenta junto al periodista la función informativa que precisa la sociedad. Opuestamente a lo que tantas veces se ha afirmado, la mejor defensa de la libertad de expresión no está (por lo menos en lo que al Periodismo se refiere) en practicar una política de puertas abiertas donde todos quepan independientemente de su sapiencia y responsabilidad para con esta ciencia-arte de incuestionable valor social; reside, en cambio, en saber garantizar una mayor capacitación y autonomía por parte del periodista, requisito indispensable para el cumplimiento eficaz y eficiente del derecho a la información reconocido a cada ser humano. Y esto pasa irremediable e irrenunciablemente por la existencia de las actuales Facultades de Ciencias de la Información y de la Comunicación.

De este parecer son Justino Sinova, María Pilar Diezhandino, Ofa Bezunartea, César Coca y, el ya desaparecido, José María Desantes:

\begin{abstract}
"Interesa que los periodistas realicen bien su trabajo, no ya para que sean respetados los derechos de la personalidad, el honor, la intimidad, la propia imagen, no ya para que en una sociedad libre la información realice también una tarea de vigilancia y control del ejercicio de la actividad pública, sino para que cada persona pueda disponer plenamente y en la práctica de su derecho natural a la información. Cabría deducir, pues, que la sociedad estaría interesada en asegurarse buenos periodistas, porque de su formación, de su recta intención, del conocimiento cabal de su responsabilidad-virtudes profesionales que se adquieren mejor o se perfeccionan más eficazmente mediante el estudio y la cultura en un ambiente universitario-depende el que cada ciudadano pueda disponer eficazmente de su derecho".

"si ser periodista significa aprender a detectar el mayor o menor valor noticioso de individuos, hechos o situaciones, a nadie mínimamente informado y consciente de la dificultad que supone ser periodista se le escapa que ahí radica justamente la síntesis de todo el saber del periodista: en la capacidad de observar, descubrir, analizar y transmitir el latido profundo de la sociedad, día tras día. Captar la noticia y su trasfondo requiere un cúmulo de saberes. Y ésa es la justificación de por qué, pese al derecho a la libertad de expresión, no todo el mundo que lo desee puede, ni acaso deba, ser periodista".
\end{abstract}

\footnotetext{
${ }^{7}$ La Universidad es el medio más indicado para la formación de profesionales aptos, capaces, competentes, especializados, autónomos (con el suficiente espíritu crítico) y conscientes de sus derechos, deberes, obligaciones y responsabilidades. La presencia del Periodismo en la Universidad como una carrera más se hace a estas alturas indiscutible.

${ }^{8}$ SINOVA, Justino: "Garantías en el ejercicio profesional del periodismo", en Telos, № 49, marzo-mayo 1997, p. 13.

${ }^{9}$ DIEZHANDINO, María Pilar, BEZUNARTEA, Ofa, y COCA, César: La elite de los periodistas, Servicio de Publicaciones de la Universidad del País Vasco, Bilbao, 1994, pp. 40-41.
} 
"La exigencia científica, sin la cual no se completa prácticamente el perfil profesional informativo, no va contra la libertad de expresión o, su variante, la libertad de información. (...) La libertad de expresión, en nuestro campo, es el modo libre de ejercitar el derecho a la información. Y el servicio a este derecho, la siempre perfectible satisfacción del debitum informativo, será tanto más libre, cuanto más conozca el informador de la fenomenología informativa, cuanto más posibilidades de cumplimiento tenga. Este conocimiento a fondo es el científico".

De esto modo, afirmaciones como las realizadas por Guillermo Escobar Roca quedan fuera de lugar, además de resultar completamente desafortunadas. Entiende este profesor en Derecho Constitucional que los defensores de la titulación del periodista esgrimen, como causa justificativa de tal razonamiento, la preservación del derecho del público a ser verazmente informado. Y como de tal requisito "no se sigue necesariamente el resultado pretendido; en otras palabras, la finalidad perseguida por la intervención no va a conseguirse con ésta, pues tanto puede haber licenciados inveraces como no licenciados veraces. (...) podemos concluir que la exigencia de la titulación (...) es inconstitucional, por cuanto implica una intervención sobre el derecho fundamental a la libertad de expresión (art. 20.1 CE) que no se encuentra constitucionalmente justificada"." Desde luego, ninguna carrera universitaria puede asegurar que la actuación de un profesional que ha contribuido a formar, será en adelante, y merced a ella, completamente honesta; pues la educación ética no tiene por objeto suplantar la libertad de la persona, más bien procura fomentar su ejercicio responsable a través de la convicción. Sin embargo, es preciso tener en cuenta que sin esa formación ética y deontológica previa será difícil que cualquier profesional pueda desempeñar adecuadamente el cometido social que se deriva de su trabajo. Todos esperamos que el médico, el abogado, el ingeniero, el farmacéutico..., al igual que el periodista, actúen honestamente, aunque su titulación no pueda garantizárnoslo. Y, a pesar de ello, no declaramos inconstitucional la obligatoriedad de la carrera universitaria específica. ¿Por qué el periodista ha de tener distinto tratamiento? Conviene también recordar que el requisito de veracidad es consustancial al concepto de información sea esta periodística o de otro tipo, aunque lógicamente sólo al periodista -precisamente por su deber social- le serán exigidos unos pasos y condiciones, con los que habrá de proceder en su actuación profesional, como comprobantes de esa veracidad. Por tanto, y con mayor razón, los periodistas se han de preparar científica y técnicamente para ser los profesionales de la información periodística que la sociedad demanda y necesita, y esta formación implicará por supuesto el comportamiento ético de su quehacer periodístico, pero también muchas otras cosas más.

10 DESANTES GUANTER, José María: El futuro de los profesionales de la información, Ediciones Universidad San Sebastián, Santiago de Chile, 1992, p. 32.

${ }^{11}$ ECOBAR ROCA, Guillermo: Estatuto de los periodistas, Tecnos, Madrid, 2002, p. 130. 
Es inconcebible que mientras, por un lado, se demanda del Periodismo una mayor responsabilidad, por otro, se le niegue cualquier perfeccionamiento o institucionalización profesional basados en la enseñanza y en la titulación correspondiente. La necesidad de recibir una formación científica adecuada se completa con la colegiación obligatoria (tal y como establece el Periodismo-profesión), ${ }^{12}$ para poder así adquirir la condición de periodista y ejercer esta determinada profesión informativa. Sin que por ello deba argumentarse que estos dos requisitos constituyen una restricción inaceptable de la libertad de expresión, pues ha de quedar claro que el derecho a la libertad de expresión es independiente del derecho al ejercicio de la profesión periodística.

En este error incurre la Proposición de Ley del Estatuto del periodista profesional. El periodista que ejerza como tal será merecedor del reconocimiento de unos derechos y obligaciones específicas que sólo le incumbirán a él, a diferencia del resto de seres humanos. Estos, a pesar de disfrutar de las mismas libertades que aquél, no verán por este motivo lesionado su derecho a poder expresarse como les dé la real gana e informar con ello de lo que buenamente les plazca. Pero, ¿cuál es el camino -según el proyecto de Estatuto- para llegar a ser merecedor de tan alta distinción? Solamente el beneplácito del empresario es capaz de dispensar este elevado y selecto rango. ¿Es esto un síntoma contumaz de profesionalidad e independencia que abogue a favor del periodista ante la pérfida acción de los poderes fácticos? Si la realidad incuestionable es que para ser periodista hay que pasar los filtros del empresario o de las centrales sindicales (que se limitan a certificar lo que el empresario ha concedido de antemano), ¿no parece más objetivo que exista primero el filtro de la Universidad, que es el habitual en todas las profesiones importantes? ¿Quién puede garantizar mejor el derecho a la información y la libertad de expresión de todo ciudadano: "el periodista silvestre, sometido a la empresa o al sindicato que le han dado la patente del ejercicio, o el periodista formado, al igual que el resto de las profesiones universitarias en un "pensum» científico y sobre una base deontológica?"13

La coincidencia de la etapa "profesionalista"14 del Periodismo con los movimientos fascistas en la mitad del siglo XX, ha hecho creer a muchos profesionales que la implantación de unos requisitos de acceso para el ejercicio del Periodismo es un intento arbitrario por renovar los viejos alegatos para controlar la libertad de

\footnotetext{
${ }^{12}$ El Colegio es el ente regulador del ejercicio profesional con arreglo a los principios intelectuales y éticos, propios del cumplimiento de derechos fundamentales del ciudadano, que el profesional, en nuestro caso, el periodista, asume como mandatario de la sociedad que, para ello, le capacita y legitima. Tal vez a Escobar Roca le convenciera más la institución colegial como medio para afianzar la conducta veraz de los periodistas. Pero siempre contando, como paso previo, con la realización de la titulación universitaria específica, pues sin ella difícilmente se conseguirá la debida capacitación.

${ }^{13}$ DE AGUINAGA, Enrique: Periodismo profesión, Fragua, Madrid, 1980, p. 296.

${ }^{14}$ Carlos Soria, alude a las tres etapas principales por las que ha discurrido la actividad periodística a lo largo de su historia: la empresarista, la profesionalista y la universalista. Para una mayor documentación véase su obra La crisis de identidad del periodista, Mitre, Madrid, 1989.
} 
Periodistas sin identidad profesional...

expresión, en aras de unos pocos privilegiados afines a las doctrinas económicas, políticas e ideológicas de turno. Sin duda, en el fondo de toda esta polémica, subyacen intereses ocultos que desean seguir manejando al periodista a su antojo y no tienen ninguna intención en que éste se convierta en un profesional titulado, independiente y autorresponsable. Pero las falacias no pueden sostenerse eternamente.

\section{SIN TITULACIÓN ACADÉMICA ESPECÍFICA Y COLEGIACIÓN NO HAY PRO- FESIÓN}

Ni siquiera los enemigos más recalcitrantes del Periodismo-profesión ponen ya en duda que la actividad periodística es ante todo un servicio público fundamental. Cuyo protagonismo se acrecienta y adquiere un valor cada vez más substancial para el apropiado desarrollo de las sociedades democráticas del presente siglo XXI. Sin embargo, no todos aciertan a comprender que tan sólo el logro del pleno status profesional permite que la finalidad comunitaria que encierra una ocupación concreta se arraigue y progrese en la dirección adecuada, por encima de cualquier interés espurio ajeno a ella. Sin la profesión este objetivo peligra, al quedar desamparada la función social de la necesaria cobertura legal y deontológica que evite a los oportunistas e indeseables hacerse con el control de la misma. Esta visión alicorta ha provocado que el Periodismo actual transite a la deriva. Sin más rumbo que el estipulado, especialmente, por los caprichosos designios del poder económico, que ha instaurado su particular concepción del vasallaje contemporáneo. Tal vez se podría argüir que la corporación profesional no cuenta con los mecanismos suficientes para hacer frente a un dominio de esta naturaleza, y que terminarían sucumbiendo a él de todas formas. Pero, no es menos cierto que, a pesar de esa inevitable ductilidad económica, la profesión -si la dejan- está capacitada para equilibrarla apropiadamente con el servicio social que ostenta sin que éste se resienta indebidamente. Así lo demuestran las profesiones con mayor tradición, como es el caso de la medicina o la abogacía. Si el Periodismo quiere seguir desempeñando el fin comunitario para el cual fue concebido no tiene más camino que el de la profesión. Su supervivencia y razón de ser dependen de ello. Y el logro de este firme propósito ha de sustentarse sobre la manifestación incontestable de dos rasgos imprescindibles que actúan a modo de columna vertebral del cuerpo profesión: la titulación académica específica y la colegiación.

No es el capricho ni el gusto por entorpecer el discurso mayoritario (al que no asiste siempre la verdad porque ésta, bien lo sabemos, no es una simple cuestión de número), el que me mueve a reclamar la concurrencia de estas dos formalidades concretas, sino una elemental ilación racional. El proceso constituyente de cualquier profesión (y no puede ser una excepción el Periodismo) se asienta inexorablemente sobre ellas, y difícilmente pueden ir adhiriéndose con el necesario sentido y utilidad los demás elementos característicos del status profesional si aquellos no están presentes. De ahí que no se pueda pasar página al tema de la titulación académica específica -como algunos quieren- hasta que no se consiga su total 
implantación. Esto es, su exigencia forzosa a todo aquel que quiera ejercer como periodista. Tras la titulación, y merced a ella, la colegiación igualmente obligatoria se erige en el medio más lógico y natural para corroborar la cualificación profesional (que la Universidad ya ha otorgado previamente) y ocuparse de todo lo relacionado con la práctica del Periodismo. De este modo queda configurada la única vía de acceso que habrá de ser demandada para alcanzar la condición de periodista, lejos de los caprichos del empresario o de las parcialidades en que pudieran incurrir los propios profesionales.

No hay razón para temer la exigencia legal de ambos requisitos, pues su imposición únicamente social o deontológica se me antoja insuficiente de cara a combatir con éxito el siempre nocivo intrusismo. Lejos de mermar el pluralismo informativo, reeditar la censura, coartar la independencia y diversidad profesional, o servir de control inquisitorial del poder político (y otras lindezas semejantes que maliciosamente esgrimen los enemigos del Periodismo-profesión) ${ }^{16}$ la titulación y la colegiación se alzan, por el contrario, como los mejores aliados para hacer frente a cualquier tipo de abuso que pretenda lesionar alguno de estos valores.

Gracias a estos dos miembros básicos del corpus profesional -cuya presencia ha de darse conjuntamente- es posible ir resolviendo con habilidad y acierto los demás atributos que conforman la verdadera profesión. El periodista profesional (apelativo que no deja de ser una elemental redundancia porque el periodista o es profesional 0 no es periodista), ${ }^{17}$ definido a través de la titulación académica específica y consiguiente colegiación, es el único indicado para asumir las tareas propiamente periodísticas y el sujeto sobre el cual han de recaer los derechos, deberes y responsabilidades que se desprenden del ejercicio profesional que lleva a cabo. De ahí lo absurdo que resulta querer elaborar un estatuto profesional cuando éste -el profesional- no existe porque es "imposible" e "indeseable" (tal y como concluyó en 1994 una Comisión constituida en el Congreso de los Diputados para estudiar las leyes del secreto profesional y de la cláusula de conciencia de los periodistas) apostar por la definición de su condición profesional, y cuando

${ }^{15}$ Lo que pretende el Periodismo-profesión no es reeditar un control estatal (más propio de las dictaduras) ni prolongar otro patronal o profesional, en su defecto, tampoco exento de despotismos. Lo que busca realmente, tal y como ya he recalcado, es introducir un reconocimiento social (a través de la Universidad, en cuya enseñanza habrá de colaborar estrechamente la entidad colegial en los términos que acuerden ambas instituciones) que certifique esa competencia para el ejercicio profesional del Periodismo, sin el menor atisbo de dudas. Ni más ni menos lo mismo que acontece en el resto de profesiones tituladas.

${ }^{16}$ Véase al respecto AZNAR, Hugo: Comunicación responsable, Ariel, Barcelona, 2005 ( $2^{\text {a }}$ edición actualizada, la 1a data de 1999), pp. 148-164. La necesaria réplica puede leerse en $R E A L$ RODRÍGUEZ, Elena: Formación y ejercicio profesional del periodista en la España del siglo XXI dentro del marco de la Unión Europea (Tomo I), tesis doctoral, Universidad Complutense, Madrid, 2003, pp. 112-133.

${ }^{17}$ La única distinción que cabe hacer entre periodistas es la de ejerciente o no ejerciente de los actos propios que comprenden el ejercicio periodístico. $Y$ el «no ejercicio» no implica en todos los casos una renuncia voluntaria y expresa a desempeñar profesionalmente las labores periodísticas. 
Periodistas sin identidad profesional...

tampoco se tiene muy claro en qué consiste eso del Periodismo. O lo inútil que es confeccionar unas normas deontológicas, por muy bien hechas que estén, cuyo cumplimiento (sin efecto sancionador más allá de la simple llamada de atención) tan sólo incumbe a aquellos periodistas que figuren inscritos en la corporación asociativa o sindical de turno que es quien normalmente las promueve. En otros casos, el desatino crece al dejar en manos de una entidad privada diferente al colectivo profesional la realización y supervisión de estos códigos de ética periodística. ${ }^{18}$ Con estos ejemplos quiero ratificar lo indicado en este epígrafe: sin titulación y colegiación no hay profesión posible. Y no la hay porque no hay mimbres para levantarla, así de claro. Estos dos requisitos son, pues, el primer paso y su malsana deformación (basada en una errónea interpretación del derecho constitucional a la libertad de expresión) vacía de contenido el auténtico significado de la profesión. Un exceso injustificable que, en ningún caso, debemos tolerar por más tiempo.

\footnotetext{
${ }^{18}$ Así ocurre, por ejemplo, con el Consejo de la Información de Cataluña (CIC). Un organismo que funciona como una fundación privada ajena, en principio, al Colegio profesional de periodistas. Aunque, en la práctica, comparten "sede" y algunos de sus miembros pertenecen igualmente al Colegio. Mi parecer es que se mezclan equivocadamente el concepto de una autorregulación comunicativa con otra estrictamente profesional. Con ello quiero defender que la existencia de un consejo de prensa, como puede ser el CIC, cuya capacidad de correctivo no va más allá de la mera advertencia, es una opción deseada, respetable y beneficiosa, especialmente con el fin de involucrar también a la empresa y al público en el comportamiento y uso responsable de los contenidos informativos que se vierten en los distintos medios de comunicación. Pero al mismo tiempo es necesario que los profesionales tengan su propio organismo deontológico (la deontología no puede ser administrada por alguien ajeno a la profesión), que aplique las sanciones pertinentes (llamada de atención, multa económica, inhabilitación, etc.) sobre aquellos profesionales que falten a los principios y normas contempladas en el código ético. Resulta incomprensible que un supuesto Colegio profesional prescinda de la correspondiente comisión deontológica, encargada de velar por la vigencia y cumplimiento de los principios éticos y deontológicos de la profesión (una de sus funciones elementales), y se la "ceda" sin más a una entidad que rebasa la composición estrictamente profesional con la excusa de una mayor independencia. ¿Por qué la mera constitución de una corporación profesional levanta todo tipo de suspicacias al respecto, e invalida a sus integrantes para un ejercicio libre y responsable de sus tareas? La presunción de independencia, así como el buen juicio y quehacer profesional, parecen ser que sólo sirven en el seno de la empresa informativa. ¿Acaso no son igualmente corruptibles los empresarios, públicos y demás colectivos a los que se implica en la ardua labor del desempeño ético y deontológico de la actividad periodística? La deontología se desnaturaliza cuando se introduce como juez y parte a elementos extraños a la profesión, pudiendo en cambio actuar como meros observadores para evitar de este modo el temido corporativismo. Sea como fuere, ambas entidades, consejo de prensa (de carácter prudencial) y comisión deontológica (de tipo cuasijurisdiccional, véase nota al pie número 57, y que abarcaría exclusivamente el área profesional), podrían convivir conjuntamente. Cada una tendría sus particulares parcelas de trabajo, aunque podrían colaborar estrechamente con el fin de que no se produjeran discrepancias notables a la hora de valorar e interpretar las actuaciones de los tres sujetos involucrados en esta actividad de clara utilidad social. Incluso no habría que descartar la posibilidad de que los componentes profesionales del consejo de prensa fueran a su vez miembros de la comisión deontológico del Colegio profesional.
} 
En 1965, Walter Lippman ya calificó al Periodismo como "profesión subdesarrollada" al carecer de estos dos elementos esenciales. ${ }^{19}$ Cuarenta años después, este noble y maltratado oficio se encuentra anclado en la misma situación, sin que se atisben, desgraciadamente, síntomas de mejora en su carrera hacia la profesión. Produce un áspero desaliento que la Proposición de Ley del Estatuto del periodista profesional que dice abogar por la profesionalidad de los periodistas sólo se acuerde de la titulación académica (sin especificar cual) para mentar que su exigencia "en los Convenios y la normativa laboral -lo que se juzga positivo para esta profesión- en nada supondrían un atentado a la libertad de expresión e información del ciudadano" ${ }^{20}$ Y de la colegiación obligatoria únicamente aluda a ella para referir su nula implantación y sustitución por otra de cariz voluntario. En cambio a este respecto, el proyecto alternativo de la FAPE da un paso más al considerar periodista al licenciado por una "facultad de periodismo, o denominación equiparable, de cualquier universidad española, así como de quién posea el título de periodista expedido por las extintas escuelas de periodismo.". Pero hierra al creer que cualquier titulación expedida por una Facultad de Ciencias de la Información o de la Comunicación (designación más extendida, no existe la denominación de Facultad de Periodismo en nuestro país) pueda servir para formar a los futuros periodistas. La colegiación tampoco encuentra aquí los ecos deseados. Aunque se apunta la existencia de "los colegios profesionales de periodistas legalmente constituidos", para ser garantes junto con la FAPE de la acreditación del ejercicio periodístico mediante la expedición del correspondiente carné.

${ }^{19}$ Citado por DE AGUINAGA, Enrique: "Periodismo colegiado", conferencia pronunciada en el Club Internacional de Prensa de Galicia, Santiago de Compostela, 6 de febrero de 1999.

${ }^{20}$ Proposición de Ley del Estatuto del periodista profesional, preámbulo. Resulta reconfortante leer que un grupo nada desdeñable de profesionales estima que la titulación académica (queremos entender que en Periodismo) es perfectamente compatible, incluso recomendable, con la tan manida libertad de expresión e información. Entonces, ¿qué le impide convertirse en la vía natural y lógica para el ejercicio del Periodismo? Otro tanto habría que decir de la colegiación, a la que se olvida en este Estatuto. Si la licenciatura no es barrera para la libertad de expresión e información, y la colegiación es una mera consecuencia de aquélla (por cuanto es la que determina quién puede o no colegiarse, es decir, quién puede o no ejercer la profesión), es razonable suponer que tampoco ésta representará un peligro para dicha libertad.

${ }^{21}$ Estatuto del Periodista de la FAPE, artículo 1ำ ("Definición”).

22 Ibíd., artículo 2으 (“Acreditación”). Esta afirmación encierra una significación más profunda de lo que en apariencia cabe deducir de ella. Los Colegios catalán y gallego no están instaurados de acuerdo con el concepto constitucional de colegiación, se desmarcan igualmente de la ley general de colegios profesionales y tampoco concuerdan -he aquí una curiosa paradoja- con la normativa legal propia de su ámbito autonómico. Aludiremos más adelante a esta cuestión. 


\section{LA CONDICIÓN PROFESIONAL DE PERIODISTA}

Los documentos del FOP y de la FAPE divergen en su concepción de quién es o deja de ser periodista. La proposición de ley redactada por el primero determina al periodista exclusivamente en función del ejercicio. Mientras que la definición de la FAPE se acerca más a la cuestión de la titulación, ${ }^{23}$ pero lo hace sólo a medias y de una forma incompleta. De acuerdo con el parecer de Enrique de Aguinaga, el primer grupo de definiciones se corresponde con una concepción del Periodismo como mera actividad, mientras que las segundas son más propias de un Periodismo que ha alcanzado ya (o, al menos, aspira a ello) el status de profesión. En opinión de Aguinaga, "La diferencia básica entre el Periodismo-actividad y el Periodismo-profesión consiste en que en el Periodismo-actividad, con fidelidad gramatical, el periodista, identificado por su actividad, actúa como tal o no es periodista, mientras que en el Periodismo-profesión el periodista, optativamente y sin dejar de serlo, puede ejercer o no ejercer el Periodismo, para cuyo ejercicio ha sido titulado".

A juicio del FOP, periodista profesional es "todo aquel que tiene por ocupación principal y remunerada la obtención, elaboración, tratamiento y difusión por cualquier medio de información de actualidad, en formato literario, gráfico, audiovisual y multimedia, con independencia del tipo de relación contractual que pueda mantener con una o varias empresas, instituciones o asociaciones. (...) El ejercicio de la profesión periodística es incompatible con el desempeño de: a) el ejercicio profesional de la actividad publicitaria, de marketing y relaciones públicas; b) la condición de policía, militar, juez o fiscal; c) los ministros y los cargos públicos de libre designación ministerial o por los órganos de gobierno de Comunidades Autónomas y Corporaciones Locales". 25 Por su parte la FAPE considera periodista a "quién está en posesión de un título (licenciatura u otro para el que se requiera estar en posesión de una licenciatura) expedido por una facultad de periodismo, o denominación equiparable, de cualquier universidad española, así como de quién posea el título de periodista expedido por las extintas escuelas de periodismo"." En el ánimo de diferenciar al periodista ejerciente del no ejerciente puntualiza que "El titular de los derechos y deberes definidos en este Estatuto es el periodista que realiza profesionalmente tareas de información de actualidad e interés público, mediante una relación laboral por cuenta ajena o por cuenta propia”.

\footnotetext{
${ }^{23}$ Como bien es de suponer cuando hago referencia a la titulación no aludo al carné acreditativo de tal condición profesional, sino a la formación académica específica que el periodista necesita conocer y dominar previamente para desempeñar su quehacer con total garantía social.

24 DE AGUINAGA, Enrique: Periodismo profesión, op. cit., p. 105.

${ }^{25}$ Proposición de Ley del Estatuto del periodista profesional, apartado I ("Del periodista profesional"), artículos 1으 ("Titularidad") y $8^{\circ}$ ("Incompatibilidades").

${ }^{26}$ Estatuto del Periodista de la FAPE, artículo 1ำ ("Definición”).

27 Ibíd.
} 
La noción de periodista basada únicamente en la idea del Periodismo como simple actividad presenta no pocos problemas para alcanzar una descripción que responda claramente a lo que en la actualidad debe ser un periodista, dada la importancia del servicio social que presta a la comunidad. Una de las dificultades es la que se refiere al acceso a la condición de periodista «profesional» y a la duración de semejante situación. Para una profesión que se considera ha de ser abierta a todo aquél que, independientemente de su situación social o formación, desee acceder a ella, ${ }^{28}$ y en la que no actúan otros requisitos previos que los establecidos arbitrariamente por el empleador, la cuestión del acceso al ejercicio queda supeditada a la decisión unilateral de otra persona ajena por completo al interesado. Es el empresario el que selecciona y hace la criba, el que decide quién reúne las cualidades para ser periodista o perder tal condición. ${ }^{29}$ Con razón indica Enrique de Aguinaga que "El comienzo del ejercicio periodístico desde el vacío profesional (el tránsito de la nada al meritoriaje) es punto propicio para todas las sumisiones por parte del empleado y para todos los abusos por parte del empleador, tan característicos de esta situación de desempleo". Es sincera la Proposición de Ley del Estatuto del periodista profesional cuando advierte que tan "sólo pretende la acreditación de la condición de periodista profesional" y que en ningún caso busca una "regulación estricta del acceso profesional" o adoptar una "habilitación previa para el ejercicio que a todos corresponde". Pues esta función la desempeña ya, y sin voluntad de contestación por parte de los profesionales del Periodismo, el empresario de turno. Este derroche de sinceridad tiene sin embargo su trampa ya que únicamente el «acreditado» de acuerdo con las bases asentadas por este proyecto de Estatuto ostentará los derechos y deberes que se contemplan en el mismo. Por tanto, sólo podrá ser periodista aquel que consiga tan preciada acreditación. Lo contrario daría lugar a un doble tipo de periodista: el periodista a secas -que ejerce el Periodismo sin derechos ni deberes- y el periodista profesional titular de los mismos. Si esto no fuera importante, ¿qué le importaría al periodista acreditado la suspensión temporal de su placet profesional? ${ }^{31}$ Esta

\footnotetext{
${ }^{28}$ Lo contrario, dicen, atenta contra el derecho a la libertad de expresión y de información que ostenta todo ser humano.

${ }^{29} \mathrm{Ni}$ siquiera los denominados freelance pueden sustraerse a la influencia del empresario, pues han de contar con su aprobación para publicar en un medio de comunicación. Internet no ha conseguido cambiar esta dura realidad, salvo para los que ya contaban con un nombre en la profesión.

30 DE AGUINAGA, Enrique: Periodismo profesión, op. cit., p. 107.

${ }^{31} \mathrm{Si}$ el carné profesional que se otorga para disfrutar de los derechos que el proyecto de Estatuto especifica -que devengan una serie de deberes que le serán asimismo exigidos- es de carácter voluntario, es decir sin fuerza obligatoria para poder desempeñar la tarea de periodista, ¿qué sentido tiene que la violación grave reiterada, de alguno de los principios recogidos en el Código deontológico que figura en el anexo, dé lugar a la retirada del carné profesional por un periodo de entre 6 meses y dos años (artículo 10ํ)? ¿Qué clase de medida disuasoria es ésta que pretende retirar una acreditación que no impide al periodista expedientado poder seguir trabajando como si nada? Ejercer como periodista significa ser automáticamente sujeto de derechos y deberes. No se puede disociar el trabajo periodístico de los derechos y deberes profe-
} 
aparentemente inofensiva maniobra lo que encierra es una habilitación a posteriori - de la que se cuida mucho de nombrar la proposición de ley- que habrá de ser renovada en un espacio de tiempo prudente, aspecto al que tampoco alude la norma aspirante a formar parte de nuestra legislación, ya que en algún momento de la vida profesional se podrá perder la suerte de haber sido designado por "una o varias empresas, instituciones o asociaciones" para desarrollar el cometido laboral de periodista.

Otra contrariedad es la obligación de demostrar que ese trabajo se ejerce de forma principal (supone la mayor parte del tiempo dedicado a la vida laboral), regular (no constituye un pasatiempo esporádico) y remunerada (representa la primera fuente de recursos económicos). "Este planteamiento crematístico de la profesión puede conducir fácilmente al absurdo de que el periodista no pueda ser un hombre adinerado, ya que en cuanto tuviese otra u otras fuentes de ingresos cualesquiera superiores a los proporcionados por el Periodismo, dejaría de ser periodista. Los ejemplos tienen que ser por fuerza pintorescos: si dos periodistas realizan exactamente la misma actividad, pero uno de ellos es titular de otras rentas que superen su retribución profesional, este último tendrá que dejar de ser periodista y dedicarse a otra profesión, a ser posible titulada (veterinario, arquitecto, abogado, químico, etc.) en la que no rija aquella especie de extravagante reducción legal de la pobreza". ${ }^{32}$ En idéntica situación se encontraría el periodista en paro, que no puede ejercer ni cobrar como periodista. Del mismo modo, el periodista que ante la precariedad laboral que padece esta profesión, no alcanzase los ingresos suficientes para llegar a fin de mes y tuviera que buscar un segundo trabajo como complemento del periodístico, deberá poner mucho cuidado en que esta nueva tarea no le robe más tiempo ni le genere mayores ingresos, además de no constituir una actividad que sea contraria a los principios periodísticos (simultanear el Periodismo con la Publicidad, por ejemplo).

Finalmente, queda lo más importante, el peliagudo asunto de qué hace un periodista para ser tenido como tal. Esta pregunta es fundamental, pues si no demuestra su condición de periodista en activo, deja de ser periodista o nunca podrá alcanzar tan noble deferencia. ${ }^{33}$ Ambos proyectos de Estatuto coinciden a la hora de describir las labores que identifican al periodista. Sólo podrán optar al cané profesional aquellos que realicen tareas (obtención, elaboración, tratamiento y

sionales que conlleva. ¿Para qué sirve entonces el carné profesional si es indiferente tenerlo o no? Si no se habilita es lógico que tampoco se pueda inhabilitar, ¿para qué molestarse pues en despojar a nadie de tan inútil posesión? Por otro lado, si el carné no es necesario para ser periodista, ¿qué sentido tienen las incompatibilidades descritas en el artículo 8?ㅜ ¿No se pretende realmente que este tipo de candidatos, al no poder disfrutar del citado carné, no puedan en verdad actuar como tales?

32 DE AGUINAGA, Enrique: Periodismo profesión, op. cit., pp. 110-111.

${ }^{33}$ Señala con buen criterio Enrique de Aguinaga, que en el sistema Periodismo-actividad a diferencia de lo que ocurre en el Periodismo-profesión, "«periodista» y "periodista en activo" son términos idénticos, ya que en este supuesto el periodista que deja de estar en activo deja de ser periodista". (Ibíd., p. 106). 
difusión) de información de actualidad e interés público ${ }^{34}$ por cualquier medio de comunicación e independientemente, por tanto, del soporte utilizado (literario, gráfico, audiovisual o multimedia) por cuenta propia o ajena para una o varias empresas, instituciones o asociaciones. Pero el Periodismo es una clase de comunicación colectiva que no comprende únicamente un carácter informativo sino que también posee una naturaleza opinativa incuestionable. Al segregar la opinión de los quehaceres periodísticos reconocidos se impide que aquellos profesionales que se dedican y viven exclusivamente de estos últimos menesteres puedan alcanzar igualmente la condición de periodista. Así lo expresa Justino Sinova, que muestra su completo rechazo al respecto:

\begin{abstract}
¿Y el periodista que realiza análisis, y el periodista que habla en tertulias, y el periodista que investiga para un libro, y el periodista que escribe un blog, y el periodista que redacta editoriales...? Todos quedan fuera. Son tan periodistas como los que hacen información en el Congreso o en el Ayuntamiento, pero el Estatuto no los considera. Según esto, ¿el editorialista, el analista y el tertuliano no merecen la protección de la cláusula de conciencia ni pueden aducir secreto profesional ante un juez? Sería absurdo $y$, además, inconstitucional, dado que nuestra ley suprema se ocupa de estas cosas, por cierto sin citar la palabra periodista al entronizar en su texto las garantías jurídicas del derecho a la información.
\end{abstract}

Este error, que no deja de serlo, tiene en parte cierta justificación. Sólo a la información periodística se le exigen unas normas específicas de calidad, veracidad y honestidad profesional que la opinión, en cambio, no demanda de la misma manera. Por ello únicamente un periodista podrá llevar a cabo las tareas informativas, mientras que las opinativas pueden quedar en manos bien de los periodistas bien de los llamados colaboradores de prensa (cuya relación comprende una especie humana tan universal como variopinta). Ahora bien, ¿pueden ser calificados de periodistas todos los mortales que ejecutan funciones exclusivamente de índole opinativo? ¿Están capacitados dichos sujetos, al mismo tiempo, para efectuar los

${ }^{34}$ Las cualidades indispensables que ha de reunir la información para ser catalogada como periodística son la utilidad, el interés, la actualidad y la veracidad. Esta información, que puede ser general o especializada, atendiendo a los criterios anteriormente establecidos, demanda, finalmente, la necesidad de ser comunicada a un destinatario que puede considerarse masivo. La especialización -que limita el contenido de la noticia y por tanto su difusión- no siempre ocasiona la pérdida de la condición de comunicación masiva, en el contexto periodístico en el cual nos movemos. Este es el caso de la prensa deportiva, económica..., o de las revistas de moda, decoración, cine, viajes, jardinería, etc., que sirven a intereses individualizados pero generalmente difundidos. Este formato, que se ajusta más al ámbito de la prensa escrita, también puede adoptarse en radio, televisión e internet. Asimismo, la interactividad que puede lograrse hoy en día a través de las nuevas tecnologías de la información y la comunicación, potencia la denominada "información a la carta" o "personalización de contenidos" que, en principio, tampoco parece alterar el requisito de amplitud de las audiencias de los medios de comunicación.

${ }^{35}$ SINOVA, Justino: "Un error básico entre algunos aciertos", en Periodistas[Fape], revista de La Federación de Asociaciones de la Prensa de España, no 2, junio-agosto 2005, p. 40. 
especiales cuidados que solicita la información periodística? Evidentemente aquí es necesario hacer una diferenciación que sin afectar a los periodistas de condición evite que todo aquel que escribe, habla o deambula en un medio de comunicación pueda ser tildado de periodista. Incoherencias que el Periodismo-actividad no sólo es incapaz de solventar sino que además contribuye a fomentar.

El problema de la definición del periodista queda resuelto cuando se adopta la vía de la titulación académica específica, y la consecuente colegiación, como único medio para conferir tal distinción. En la concepción del Periodismo-profesión, el periodista ya no puede seguir cimentando la conquista de su condición por la simple realización de la práctica profesional. El periodista ya no es el que hace esto o lo otro, sino el que está capacitado para hacer esto o lo otro, el que se ha preparado convenientemente para el ejercicio profesional del Periodismo..., esté o no desempeñando cualquiera de los actos propios que lo caracterizan. La cuestión de la formación adquiere así un peso fundamental en el proceso de profesionalización del Periodismo. Sólo una enseñanza de calidad fuera de toda duda conduce a la existencia de periodistas competentes y altamente cualificados, que hacen posible a su vez una información, una opinión y una comunicación de indiscutible categoría. Esa educación debe estar en condiciones de responder a las exigencias que le demandan tanto la sociedad como una información y comunicación periodística en continuo desarrollo. ${ }^{36}$

De este modo el profesional de la información periodística no depende de que un empresario le contrate para iniciarse como periodista. La idoneidad para alcanzar el título de periodista «profesional» no recae en un número determinado de años de ejercicio, ni en que se demuestre una práctica principal, habitual y remunerada del Periodismo. En todo caso estas son consecuencias producidas por el desempeño de la propia actividad profesional, pero que en ningún caso pueden ser aceptadas como condición sine qua non para determinar quién es apto o quién no para ser considerado periodista y poder actuar como tal. El periodista así definido podrá ejercer o no ejercer (pues la condición de periodista nunca cesa), con lo que será preciso establecer qué se entiende por ejercicio profesional del Periodismo. En boca de Aguinaga "una sociedad periodística demuestra su desarrollo y plenitud cuando, por superación, deja de preocuparse de la definición de periodista para preocuparse en la definición del ejercicio profesional del Periodismo". ${ }^{37}$

Pero no sólo es necesario precisar este ejercicio profesional para distinguir al periodista ejerciente, sino que además resulta indispensable para delimitar qué "funciones", "tareas", "trabajos" o "actos" son propios y exclusivos del que tiene la condición de periodista y deben ser preservados de cualquier tipo de intrusismo. Para lo cual de Aguinaga plantea desechar la definición del periodista por su

\footnotetext{
${ }^{36}$ Y la mejor forma de adquirir esa capacitación, lejos de los caprichos del empresario o del corporativismo de la organización profesional, es -como ya hemos recalcado con anterioridaduna buena enseñanza universitaria del Periodismo.

${ }^{37}$ DE AGUINAGA, Enrique: Periodismo, profesión, op. cit., p. 176.
} 
actividad, $^{38}$ y sugiere una definición objetiva del ejercicio profesional del Periodismo que recoja, por un lado, la naturaleza misma del trabajo periodístico, en la que se establezca el denominador común de todos los actos propios de la profesión periodística (definición sintética, genérica o cerrada), y por otro, una relación detallada en la que se especifiquen cuáles han de ser esos actos o especialidades en que aquella generalidad se proyecta (definición analítica, enumerativa o abierta). Este análisis pormenorizado, que nos remite sin ambages a la existencia de un único periodista y de un solo Periodismo, resuelve sin excesivas dificultades la enorme problemática que parece girar en torno a qué puestos y en qué medios cabe limitar la entrada a los que dispongan de la consabida titulación académica específica y la correspondiente colegiación; es decir al cometido periodístico que exclusivamente habrá de ser desempeñado por periodistas. Propuesta que nadie hasta el momento ha sido capaz ni tan siquiera de insinuar en sus términos más simples.

\section{LA INELUDIBLE DIFERENCIACIÓN DE LA INFORMACIÓN PERIODÍSTICA}

Asistimos, en el momento presente, a una viciada interpretación no sólo del concepto de periodista sino igualmente de la noción de Periodismo, que intenta equiparar las distintas formas informativas que se engloban bajo el común denominador de la Comunicación Social. No podemos caer en simplificaciones tales como manifestar que todo contenido mediático, por el mero hecho de ser difundido a través de un medio de comunicación social, puede ser ya considerado Periodismo con este único y fugaz requisito. Empero, nada más alejado de la realidad, aunque existan múltiples definiciones (de escaso cariz científico, todo hay que decirlo) empeñadas en aparentar lo contrario. De igual modo, tampoco ha de aceptarse como acto propio del ejercicio periodístico cualquier actividad informativa que sea encomendada a un periodista. Medio de comunicación social y actividad informativa no son, pues, sinónimos de Periodismo o de periodista. Hay otras clases de información que emplean también los grandes medios de difusión de masas y, sin embargo, poco o nada tienen que ver con el Periodismo. Asimismo los contenidos

\footnotetext{
${ }^{38}$ Si bien ésta no deja de ser una definición del ejercicio profesional, aunque lo sea de modo indirecto y subjetivo.

${ }^{39}$ Aquellos que estén interesados en conocer dicha propuesta pueden consultar DE AGUINAGA, Enrique: Periodismo, profesión, op. cit., pp. 201-232. La revisión actualizada de la misma se encuentra en REAL RODRÍGUEZ, Elena: op. cit., tomo I, pp. 133-160. Un extracto de esta tesis doctoral referente a estas cuestiones se ha publicado bajo el título "Un intento por clarificar los actos propios del ejercicio periodístico" en el volumen 11 de la revista Estudios sobre el mensaje periodístico, 2005, pp. 129-151. Esta proposición no aspira a convertirse en un proyecto cerrado sin posibilidad de diálogo. Al contrario, pretende ser el argumento inicial de debate que logre dar el empujón definitivo al proceso constitucional del Periodismo como profesión. Estas sugerencias podrán, pues, perfeccionarse (si así lo estima oportuno el órgano de representación de todos los periodistas, que no ha de ser otro que el Colegio profesional) hasta alcanzar una redacción definitiva que habrá de plasmarse en el nuevo Estatuto Profesional.
} 
que se emiten a través de dichos medios masivos no son exclusivamente informativos. El Periodismo, dentro de la Información y la Comunicación Social, posee unas maneras y cualidades específicas que le procuran un carácter singular y único, que no debe ser asimilado con otras formas informativas y comunicativas ciertamente parecidas pero ni mucho menos idénticas. Y aquí, como indica Gabriel Galdón "radica el problema. En que aún andamos mezclando Comunicación e Información. En que las fronteras entre Publicidad, Relaciones Públicas, Comunicación Institucional, Narrativa Audiovisual y Periodismo no están claramente definidas. En que bajo el título de periodista cabe el sesudo director de "The Economist" hasta el paparazzi más desvergonzado y amoral. Es creer que todo lo que se publica es información y, por tanto, le asiste el sacrosanto derecho a la libertad de expresión...".

Y es esta una asignatura pendiente que no hemos acometido aún con el rigor necesario, cuyo injustificable y contraproducente retraso no debe ser achacado únicamente a los profesionales sino principalmente a las Facultades de Ciencias de la Información y de la Comunicación. Al acierto de diversificar los estudios de comunicación en tres ámbitos diferenciados (Periodismo, Comunicación Audiovisual y Publicidad y Relaciones Públicas), tal y como consta desde 1991, se observa, sin embargo, que a pesar de los años transcurridos desde el acceso de estas carreras a la Universidad, en la práctica esa delimitación no parece tan clara como debiera. Si resulta obvio que no es lo mismo la información periodística que la publicitaria y la propia de las relaciones públicas, ¿por qué, sin embargo, confundimos constantemente los actos propios de la actividad profesional del periodista con los que deberían ser exclusivos del publicitario o el relacionista ${ }^{41}$ ? Y esta confusión se deja ver manifiestamente tanto en el actual y futuro diseño de los planes de estudios de las Universidades ${ }^{42}$ como en el concepto de periodista que hemos analizado con anterioridad en la Proposición de Ley del Estatuto del periodista profesional, que no especifica el tipo de información a la que alude y advierte que ese trabajo informativo le puede venir dado al periodista por una 0 varias empresas, instituciones o asociaciones.

\footnotetext{
40 GALDÓN, Gabriel: La enseñanza del periodismo, CIMS, Barcelona, 1999, p. 18.

${ }^{41}$ Término de nuevo cuño que establece el DRAE para referirse al profesional de las relaciones

${ }^{42}$ No hay más que observar el apartado referente «a los perfiles profesionales y sus competencias» que figura dentro de la propuesta de la nueva titulación de Grado en Periodismo, realizada por los decanos de las distintas Facultades de Ciencias de la Información y de la Comunicación en 2004 para la ANECA, con vistas a su adaptación al nuevo Espacio Europeo de Educación Superior (EEES). Este documento se puede encontrar en www.aneca.es y ccc-web.uab.es/ pr.aneca.comunicacion/aneca comunicacion.htm. La autora de este artículo ha disertado acerca de las más que palmarias inconsistencias que encierran dicha propuesta en un texto que lleva por título "Algunas interrogantes en torno a los estudios de Periodismo ante el nuevo Espacio Europeo de Educación Superior", que está publicado en el no 10 de la revista Cuadernos de Información y Comunicación (CIC), 2005, pp. 267-284.

${ }^{43}$ Tampoco el texto de la FAPE es muy clarificador al respecto.
} públicas. 
No hay que ser adivinos para colegir que una de esas labores informativas tiene lugar en los gabinetes de prensa o de comunicación, es decir, en la denominada Comunicación Empresarial e Institucional, tanto en el ámbito público como privado, donde los periodistas están siendo reclutados con especial interés en las dos últimas décadas. Un alto porcentaje de los profesionales que trabajan en los gabinetes de comunicación son realmente periodistas, pues, acreditan su título universitario en Periodismo. Pero difícilmente pueden ser considerados periodistas ejercientes, dada la naturaleza opuesta de su tarea con el cometido específico del ejercicio periodístico, y que el Estatuto del FOP se esfuerza denodadamente en recalcar. De ahí que todo sea si cabe más equívoco. Ambos, periodista y publicitario y relaciones públicas, tratan con información, es cierto, y esa información es transmitida a la opinión pública, sin embargo no toda información es información periodística. Existen otros usos de la información de actualidad, ${ }^{44}$ asimismo de índole persuasiva (aunque con un cariz más acusado), pero donde prima fundamentalmente una utilización interesada de la misma, ${ }^{45}$ como son: la Propaganda (persuasión ideológica), la Publicidad (persuasión comercial), las Relaciones Públicas y el Marketing Político. ${ }^{46}$ José María García Casasnovas, director de comunicación de Iberdola, es plenamente consciente de este matiz diferenciador, por lo que no cabe considerar la Comunicación Institucional y Empresarial como una simple especialización de la profesión periodística:

"La comunicación institucional de las empresas es fundamentalmente una acción de comunicación. Evidentemente, transmite una información pero esa información debe ser motivada y con un objetivo concreto, de acuerdo con la estrategia de la empresa. La sintonía entre la empresa, su estrategia y su comunicación debe ser total. Bajo este punto de vista, la comunicación empresarial es algo más que una acción informativa, que también lo es, ya que debe integrarse y ser una herramienta al servicio de la estrategia empresarial".

Dada la importancia que tienen los medios de comunicación y, por tanto, la colaboración de los periodistas para el trabajo de los gabinetes de comunicación, la presencia de estos en los departamentos de comunicación de las empresas o

\footnotetext{
${ }^{44}$ En las que si bien es cierto ésta no es una cualidad tan marcada como en el Periodismo, puede dar lugar a ambigüedades importantes si no se hacen las oportunas distinciones.

${ }^{45}$ El bien común cede su primacía en aras de un interés particular, que no pierde por ello necesariamente su legitimidad. Queremos, así, afirmar que estos otros usos de la información de actualidad no son perversos en sí mismos, sino que también responden a una utilidad social, aunque de distinta naturaleza. Es preciso, no obstante, no perder el referente de los valores éticos exigibles también a estas otras actividades profesionales.

${ }^{46}$ Para profundizar en las diversas formas, modos y clases de Información y Comunicación Social se puede consultar, por ejemplo, BENITO JAEN, Angel: La invención de la actualidad, Fondo de Cultura Económica, Madrid, 1995.

47 FAPE: "Comunicación institucional, una especialidad de la profesión informativa", dossier especial, en FAPE, nํ30, abril-mayo 1998, p. 33. (Sin firma)
} 
Periodistas sin identidad profesional...

de los organismos públicos e instituciones, así como en las asesorías o consultorías externas, ha sido de gran utilidad por su conocimiento de las rutinas periodísticas. Sin embargo, para la labor que los periodistas desempeñan en los gabinetes de comunicación no les sirve únicamente lo aprendido para su quehacer periodístico, requieren de otros conocimientos adicionales que van más allá de las destrezas que una titulación específica en Periodismo puede proporcionar y que, curiosamente, coinciden con la formación que procura la Licenciatura en Publicidad y Relaciones Públicas. De este parecer es el ya citado José María García Casasnovas:

"Los periodistas profesionales aportan sin duda unos conocimientos y experiencia, en su caso, en cuanto a las técnicas informativas y comunicativas. No obstante, la comunicación de empresa exige otros conocimientos adicionales, como son el conocimiento de la empresa, interna y externamente, el conocimiento de los procesos productivos, conocimientos que van más allá de una formación meramente periodística, es decir, no se trata de ser un mero intermediario en la información con la sociedad sino ser un agente más en el desarrollo de la estrategia empresarial".

Urge, pues, que los profesionales hagan los deberes y antes de nada establezcan con claridad qué se entiende por las distintas actividades profesionales de la Información y de la Comunicación Social, y cuáles son los actos profesionales propios de cada una de ellas. A este respecto deberíamos ayudar desde las Facultades de Ciencias de la Información y de la Comunicación y no, por el contrario, a aumentar más el embrollo terminológico. Es cierto que, en nuestro descargo, podríamos argumentar que nos limitamos a responder a las necesidades formativas que nos reclaman las empresas profesionales. Pero, una cosa es limitarse a servir a las empresas (y en los términos en que éstas lo expliciten) y, otra bien distinta, es hacerlo aún a costa de que dichas demandas vulneren los conceptos y principios básicos de las más principales necesidades sociales que se desprenden a su vez de cada una de las actividades profesionales que estamos contribuyendo a formar. $\mathrm{O}$, lo que es igual, si educamos periodistas no podemos hacerlos pasar por propagandistas, publicitarios o relacionistas, y viceversa. $Y$, además, asumir que ya que esto es lo que "es", debemos instaurarlo como lo que "debe ser".

\footnotetext{
${ }^{48}$ Ibíd.

${ }^{49}$ No quiero decir que los periodistas, que hasta no hace mucho han acaparado los puestos de las plantillas de los gabinetes de comunicación, ya no resulten útiles en ellos, o que no deban dedicar su quehacer profesional al ámbito empresarial e institucional, o incluso que las Universidades les formen para ello (en aras de responder a esta demanda) dentro de un título de postgrado específico. Simplemente quiero reseñar que el trabajo que un periodista puede llevar a cabo en los gabinetes de comunicación no puede ser considerado, por un lado, como trabajo periodístico $y$, por otro, como un acto exclusivo de estos profesionales, por lo que no pueden ser reconocidos como periodistas en ejercicio.
} 


\section{LA COLEGIACIÓN SUPLANTADA}

Los Colegios profesionales son corporaciones de Derecho Público que integran a personas de intereses comunes a cambio de encomendarles algunas funciones, de especial provecho comunitario. Así, la simple presencia de bienes privados de los profesionales no justifica ni legitima la utilización de la forma colegial. Para eso son suficientes las libertades de asociación y sindicación. ${ }^{50}$ Sólo la tutela de beneficios públicos relevantes del ejercicio de las actividades profesionales corresponde en exclusiva a los Colegios profesionales. De este modo, únicamente las profesiones tituladas que cumplen funciones públicas de trascendencia social están capacitadas para pedir la creación de un Colegio profesional. La colegiación remite de manera indispensable a una titulación determinada, normalmente universitaria, pues su finalidad esencial es la de garantizar a la sociedad que las personas que ejerzan esa profesión han sido convenientemente preparadas. El requisito de la titulación superior como medio único de acceso profesional, resuelve la exigencia de colegiación como una consecuencia lógica. El Colegio acepta a todos aquellos que demuestran haber superado los estudios académicos requeridos para el desempeño de una profesión concreta. No otorga a capricho la condición profesional. Potestad, repetimos una vez más, que ha de ser vista como una salvaguardia social y nunca como un ataque discriminatorio contra las libertades de asociación y de elección de profesión u oficio. La necesidad de servir a un interés público superior justifica tanto la demanda de titulación como la obligatoriedad de la colegiación. Éste es el razonamiento que ofrece el Tribunal Constitucional (TC), al indicar que el Colegio profesional tiene en sus manos la función de garantizar que el ejercicio de la profesión -que constituye un servicio al común- se ajuste a las normas o reglas que aseguren tanto la eficacia como la eventual responsabilidad en tal ejercicio, que en principio, por ${ }_{51}$ tra parte, ya ha garantizado el Estado con la expedición del título habilitante.

La no obligatoriedad de pertenencia a los Colegios profesionales de periodistas existentes (Galicia y Cataluña son los únicos que hasta el momento se han constituido), así como la falta de consenso acerca de cuál debe ser la titulación

\footnotetext{
${ }^{50}$ A diferencia de las asociaciones y los sindicatos, los fines de los Colegios profesionales son de carácter institucional, vienen imperados por la misma naturaleza de la profesión de que se trata. Mientras la creación de las otras agrupaciones es libre, los Colegios han de constituirse a petición de los profesionales interesados por voluntad directa estatal o autonómica, mediante una ley formal. Poseen además un carácter forzoso, es de pertenencia obligatoria para aquellos profesionales a cuya actividad el Colegio se refiera (sólo quedan dispensados de esta obligación aquellos profesionales funcionarios y contratados al servicio de las Administraciones públicas que tengan como destinatarios de sus actos profesionales a la propia Administración, lo cual no deja de ser discutible). Disfruta de exclusividad territorial y su personalidad jurídica pública posibilita la impugnación de sus acuerdos a través de la vía contencioso-administrativa.

51 STC 89/1989, de 11 de mayo.
} 
académica requerida, ${ }^{52}$ condicionan en gran medida su viabilidad y funcionamiento como tales Colegios profesionales. Nadie pone en duda la trascendencia pública del Derecho a la información (deber substancial del periodista). Si la licenciatura en Periodismo fue diseñada para proporcionar los oportunos y precisos conocimientos en este campo profesional, ${ }^{53}$ la labor del Colegio es, pues, la de asegurar en aras de la eficacia y la responsabilidad social -tal y como precisa el TC- que únicamente los que han superado dichos estudios ejerzan como tales periodistas. Sin la titulación no se concibe el Colegio profesional. Si aún existiendo dicha titulación, ésta no se exige, el Colegio puede resultar una entelequia. Los Colegios de periodistas se han incapacitado, de este modo, para la actuación como tales entes colegiales. No son competentes para certificar la correcta formación académica y profesional de nuestros periodistas. ${ }^{54} \mathrm{Y}$ como consecuencia de ello, han perdido la oportunidad de aclarar qué es el Periodismo, cuál es el sentido y finalidad de la pretendida profesión periodística, quién es periodista y en qué consiste su ejercicio profesional, y, por lo tanto, qué tareas le son exclusivas y deben ser ejecutadas solamente por él. ${ }^{55}$ En el fondo de este cúmulo de despropósitos subyace un preocupante desconocimiento del periodista sobre sí mismo y la ocupación que lleva a cabo, amén de la gran divergencia de pareceres (casi siempre interesados y falaces) que relegan al Periodismo a la concepción de simple oficio.

\footnotetext{
${ }^{52}$ La licenciatura en Periodismo es para el Colegio catalán una de las muchas posibles, pues todo aquel licenciado en lo que sea que ejerza como periodista es considerado como tal. Mientras que para el Colegio Gallego además del Periodismo también es aceptada la licenciatura en Comunicación Audiovisual, siempre y cuando se desempeñen labores «informativas» (¿periodísticas, tal vez?). A pesar de que en octubre de 2002 ambas corporaciones decidieron impulsar la creación de una Federación de Colegios de Periodistas, no se han molestado lo más mínimo en aunar criterios, y, así, se puede dar la ingeniosa circunstancia de que una persona pueda ser investida como periodista "colegiado» en una Comunidad Autónoma pero no en la otra.

${ }^{53}$ Presuponemos que bajo esta denominación el Estado estaba pensando en periodistas y no en abogados, médicos, informáticos, sociólogos, historiadores, filólogos..., que ya tienen su propia titulación universitaria. Hacemos esta reflexión por cuanto queremos ver en la decisión estatal una firme respuesta a una señalada utilidad social, y no un capricho innecesario o una imposición dictatorial, como otros pretenden hacernos creer. Es decir, que dicha licenciatura nació en respuesta a una notoria demanda comunitaria, a saber: la de formar periodistas vocacionales, completos, competentes, críticos, responsables, creativos y preocupados por su quehacer peculiar y específico diario. Todo ello de cara a cumplir con la mayor seriedad posible las funciones que la sociedad les ha confiado.

${ }^{54}$ Admitir la licenciatura en Periodismo como una de tantas permitidas, aunque la coloquemos en primer lugar (Cataluña), o como la otra en liza (Galicia), es de una tibieza inaceptable que habla de la fragilidad e ineptitud que caracterizan a nuestros pseudocolegios profesionales. Clara manifestación de la denigrante sumisión a la que se ha visto sometida la misma actividad periodística que, en su día, dichas entidades prometieron a toda costa defender. ¡Menuda ironía!

${ }^{55}$ Situación que favorece el alto grado de confusión que distingue en la actualidad todo lo que es y rodea al Periodismo.
} 
La colegiación voluntaria agrava aún más este despropósito colegial. Si el Colegio no actúa sobre todos aquellos que trabajan como periodistas para cerciorarse de que disponen de la habilitación necesaria, difícilmente puede erigirse en la organización que vele por el cumplimiento de la ética y la deontología en el seno de la profesión. La disciplina del Colegio -que ejerce dicho cometido aplicando las sanciones oportunas- sólo alcanza a los que están colegiados, y si los profesionales no tienen obligación de colegiarse..., ¿cómo se puede demandar la observancia de los principios deontológicos a todo el colectivo profesional? Y si además la reacción ante tal desolador panorama es la de ceder amigablemente la realización y supervisión de las cuestiones éticas y deontológicas..., ¿qué más se puede pedir? ${ }^{56}$ Aún tenemos que aprender que las libertades de expresión e información no pueden estar por encima del bien y del mal, especialmente cuando se trata de un comportamiento profesional. La existencia de organismos de autocontrol cuasijurisdiccionales $^{57}$ no debe ser motivo de alarma ni suponer un retroceso histórico, sino todo lo contrario, asumir que el Periodismo puede y debe ser una profesión como las demás. ${ }^{58}$ Asimismo, esta realidad colegial tan peculiar resulta inoperante para encargarse de todo lo relacionado con la ordenación de la profesión, ni tan siquiera podría atribuirse en exclusiva la representatividad del conjunto profesional.

Si esta clase de Colegios no están capacitados para asumir las competencias más elementales que la Ley les atribuye y el Estado les confía (en nombre de la sociedad)..., ¿para qué los queremos? Es obvio que para muy poco. Externamente tienen la forma de Colegios profesionales pero internamente, no nos engañemos, funcionan como asociaciones privadas. Las Leyes autonómicas que crean los dos Colegios profesionales de periodistas existentes, se acogen a una normativa general estatal y autonómica que no sólo prescribe la colegiación obligatoria para las profesiones tituladas, sino que además señala a este tipo de profesiones como las únicas autorizadas para tener un Colegio profesional. Por lo que al vulnerar ambos condicionantes cabría pensar en su invalidez jurídica. Sin embargo, la ambigua actitud del TC, que sin establecer las distinciones oportunas posibilita la coexistencia de colegios profesionales -ya estatales ya autonómicos- de adscrip-

\footnotetext{
${ }^{56}$ Véase nota al pie número 18.

${ }^{57}$ El autocontrol informativo no es jurisdiccional porque no aplica leyes jurídicas, sino normas éticas o deontológicas. Decimos que es cuasijurisdiccional porque, a diferencia de los prudenciales (que no son vinculantes y se limitan a llamar la atención sobre comportamientos éticamente incorrectos o indeseables), pueden imponer ciertas sanciones y tener cierto grado de obligatoriedad. Sanciones que van desde la multa económica hasta la inhabilitación temporal o definitiva para el ejercicio profesional (que en ningún caso podría impedir ni lesionar el derecho personal a seguir expresándose libremente).

${ }^{58}$ ¿Por qué no hay nada de malo en sancionar a un médico (abogado, arquitecto, enfermero, etc.) que incumple con conocimiento y voluntariedad su código ético, y cuándo se trata de un periodista es anticonstitucional y volvemos otra vez a la España franquista?

${ }^{59}$ Constituyen fines esenciales de los Colegios profesionales la ordenación del ejercicio de las profesiones, la representación exclusiva de las mismas y la defensa de los intereses profesionales de los colegiados. Asimismo, velarán por la ética y la dignidad profesional en el desarrollo de la profesión y por el respeto a los derechos de terceros.
} 
Periodistas sin identidad profesional...

ción voluntaria, ${ }^{60}$ permite que no sean declaradas inconstitucionales. ¿Para qué entonces el legislador, en un momento dado, establece una cosa y luego, sin declarar la invalidez de la primera norma, autoriza otra totalmente contraria? Misterios del Derecho.

Tras lo expuesto hasta ahora resulta todavía más sorprendente la fórmula que el FOP, a través de la Proposición de Ley del Estatuto del periodista profesional, pretende implantar para acometer las labores concernientes a la acreditación de los periodistas y al control deontológico de la profesión periodística. El FOP ha pensado que lo más conveniente para ello es abandonar el modelo propio de la autorregulación y promover la constitución de un órgano público (muy parecido al formato de los Consejos Audiovisuales) que difiere claramente del procedimiento colegial ya conocido y que no admite comparación posible que alimente hacia este último idénticos recelos. Con tal fin propone la creación del Consejo Estatal de la Información, definido como "un organismo público independiente del poder ejecutivo y que rinde cuentas de su actuación al poder legislativo", compatible con los Consejos Autonómicos que al efecto se organicen. Su función genérica se centraría en fomentar y proteger "los derechos a la libertad de expresión e información y de modo específico el derecho del público a recibir información y los derechos profesionales declarados en este Estatuto". 63 Estaría formado por 22 miembros, elegidos por mayoría de dos tercios de las Cortes Generales (11 el Congreso y otros 11 el Senado) entre personas pertenecientes a las siguientes categorías: 8 periodistas, 4 representantes de las asociaciones empresariales de la comunicación, 2 juristas de reconocido prestigio, 4 representantes sindicales y 4 representantes de asociaciones de consumidores, radioyentes o telespectadores. Su sostenimiento económico correría a cargo de los Presupuestos Generales del Estado. Asombra igualmente que el cariz otorgado a la Comisión Deontológica de este organismo, encargada de la supervisión del cumplimiento del Código ético que figura en el anexo del Estatuto Profesional, ${ }^{64}$ sea de orden cuasijurisdiccional. Por su parte, el Estatuto que promueve la FAPE deja, en cambio, la acreditación en manos de este ente asociativo y de los Colegios profesionales de periodistas legalmente constituidos, sobre los que debería recaer, sin embargo, en solitario

\footnotetext{
${ }^{60}$ Lo que vacía de contenido las características definitorias específicas que las Leyes estatal y autonómicas señalan para los Colegios profesionales.

${ }^{61} \mathrm{El}$ hecho de que los Colegios sean creados mediante una Ley no debe depositar sobre ellos la sospecha de servir de instrumento de control político. Nada más alejado de la realidad. Sin Colegios profesionales ese control político crecer peligrosamente sin el contrapeso de la ardua y siempre deseable labor de supervisión profesional con las garantías sociales y jurídicas oportunas. No debemos caer en el error de confundir Estado con poder ejecutivo, ni asimilar a éste las labores legislativas y judiciales, al menos en las sociedades democráticas que se precien de serlo.

${ }^{62}$ Proyecto de Ley de Estatuto del Periodista Profesional, apartado IV ("De los Consejos de la Información"), artículo 25ํ ("Consejo Estatal de la Información”).

${ }^{63}$ Ibíd.

${ }^{64}$ Que al convertirse en Ley perderá su naturaleza ética y deontológica.
} 
este cometido. ${ }^{65}$ No alude expresamente a las funciones éticas y deontológicas, que prefiere dejar a la libre iniciativa de los periodistas.

Se desecha la vía propiamente deontológica (instauración de una comisión al uso dependiente del Colegio profesional) por cuanto se interpreta que ello daría lugar irremediablemente a una situación de corporativismo del que hay que huir como de la peste (el periodista, al parecer, sólo se le puede presumir independiente, juicioso y honesto en el seno de la empresa informativa), amén de la falta de transparencia que dicha opción iba a generar por no aceptar como miembros a personas externas al colectivo profesional (como si el único remedio a dicho mal fuera la imposición de integrantes ajenos a la profesión). Por lo cual se decide que el órgano ideal encargado de supervisar el cumplimiento de la ética y la deontología periodística ha de ser de índole privado y autónomo del poder profesional, conformado por representantes de cada una de las partes que intervienen en dicho proceso informativo. ${ }^{67}$ Sin embargo, el FOP parece haber dado con una solución mejor. Puede que la profesión esté proscrita para tamaño cometido (no conviene que actúe como juez y parte pues esto, independientemente de su mayor conocimiento, le nubla su sano juicio), pero no así el poder legislativo (valedor de los derechos de todos y siempre incorruptible). Quien será, finalmente (aunque de una forma indirecta), el encargado de enjuiciar la actuación informativa llevada a cabo por empresas y periodistas, además de decidir quién puede ser investido como periodista. Es obvio, que con este peculiar modelo se ha sustituido el control profesional por un peligroso control político. La confusión se ha multiplicado.

\section{EL DESIGUAL TRATO DE LA MIGRACIÓN EN EL EJERCICIO DEL PERIODISMO}

No quiero terminar estas puntualizaciones sin referirme brevemente a la condición del periodista extranjero. El Periodismo está lejos de poder ser considerado una profesión como tal en los restantes estados que conforman la denominada Unión Europea (UE), salvo en el caso de Italia. Para evitar que la especial realidad

\footnotetext{
${ }^{65}$ Una asociación por muy mayoritaria que sea no puede equipararse al Colegio profesional y pretender arrogarse, por esa simple razón de número, sus funciones exclusivas.

${ }^{66}$ Recordemos que la FAPE ha adoptado un Consejo Deontológico que funciona de manera muy semejante a su homónimo catalán, aunque el primero -y por mucho que se esfuerce la FAPE en disimularlo- está ligado al organismo asociativo que lo respalda, reconoce y alimenta, con lo que lejos de ser una institución completamente independiente actúa como una Comisión Deontológica de la FAPE, que cortésmente le ha conferido sus prerrogativas al respecto.

${ }^{67}$ Este es el camino que ha dado lugar al CIC y al Consejo Deontológico alentado por la FAPE.

68 Parece mentira que se pongan tantos reparos a la exigencia de la titulación académica específica y la consiguiente colegiación para acceder al ejercicio profesional del periodismo, en aras de una supuesta incompatibilidad con la libertad de expresión. Y no se vea ningún tipo de riesgo para ella en el hecho de fomentar un control político del ejercicio y de la deontología periodística. Lo primero es reeditar la dictadura franquista y lo segundo un acto de coherencia democrática. Sólo el interés más depravado podría incurrir en tamaño despropósito. Para profundizar en estas cuestiones véase REAL RODRÍGUEZ, Elena: op. cit., tomo I, pp. 245-302.
} 
italiana, así como los requisitos exigidos en otros países miembros como Portugal, Francia, Bélgica y Luxemburgo (además de las notables divergencias existentes respecto a lo que en cada estado se entiende por Periodismo), ${ }^{69}$ dificulten la libre circulación de periodistas dentro del territorio de la UE, las organizaciones de periodistas y empresarios de la comunicación han manifestado en diversas ocasiones que la mejor solución es la aceptación mutua de acreditaciones (ya que no se ponen de acuerdo en un modelo común), es decir, que todo aquel que sea distinguido como periodista por un país miembro lo será igualmente en el resto. Este es el parecer que recogen ambos proyectos de Estatuto del Periodista, que hacen extensible su reconocimiento a corresponsales y enviados especiales de terceros países, previo requisito de reciprocidad. No obstante, esta solución, lejos de igualar las cualificaciones entre periodistas de otros países miembros y originarios del estado miembro de acogida, termina por provocar la discriminación contraria: ahora son los nacionales los que se sienten injustamente tratados frente a los inmigrantes, ya que han de cumplir forzosamente con unas condiciones que no les son requeridas a los demás periodistas de la UE y de terceros países con condición de reciprocidad. Asimismo, esta opción perjudica seriamente a aquellos estados que deseen optar individualmente por la profesionalización de la actividad periodística, puesto que la profesión queda desamparada frente al oficio (que iguala incomprensiblemente su condición respecto a aquélla). El derecho a la libre circulación de personas -al igual que ocurre con el derecho a la libertad de expresión- no puede ser utilizado a modo de barrera infranqueable que impida, ante la ausencia de pactos globales, a la actividad periodística evolucionar finalmente hacia el estrato profesional. Sería más dañino y contraproducente que el supuesto bien que se quiere preservar.

La Unión Europea, que ha declarado en reiteradas ocasiones que no intervendrá en este conflicto, debe, al menos, permitir que en los estados miembros interesados el Periodismo pueda quedar constituido como una profesión más. La libre circulación de periodistas procedentes de otros países miembros que no acometan esta transformación, estaría asegurada -de acuerdo con lo estipulado en la Directiva europea ${ }^{70}$ - si en cada estado de la UE se promoviera una titulación académica específica (expedida por las autoridades competentes y que preparase para el ejercicio de la profesión) semejante a la establecida en los países que sí hayan optado por su profesionalización. De esta forma, la titulación se perfila como la pieza fundamental que, por un lado, haga realidad la constitución profesional del Periodismo y, por otro, posibilite un punto de encuentro entre aquellos países que apuesten sin ambages por el Periodismo-profesión y los que, en cambio, prefieran

\footnotetext{
${ }^{69}$ Para conocer estas peculiaridades se puede consultar REAL RODRÍGUEZ, Elena: op. cit., tomo I, pp. 307-406.

${ }^{70}$ Directiva 2005/36/CE del Parlamento Europeo y del Consejo, de 7 de septiembre de 2005, relativa al reconocimiento de cualificaciones profesionales (Texto pertinente a efectos del EEE). Diario Oficial no L 255 de 30/09/2005, pp. 22-142.
} 
dilatar caprichosamente su instauración. ${ }^{71}$ En este sentido el proceso de convergencia educativa que se está llevando a cabo en el seno de la UE, de cara a establecer próximamente un Espacio Europeo de la Educación Superior (EEES), permitirá desarrollar títulos universitarios comunes (si no iguales al menos sí fácilmente compatibles y comparables) que disminuyan, o incluso logren hacer desaparecer, las trabas actuales en lo que a las distintas exigencias formativas de los profesionales se refiere, con el objeto de impulsar la libre circulación de los mismos entre los diferentes países miembros. Por tanto, resulta un despropósito la sugerencia de los periodistas y empresarios de la comunicación europeos que, sin reparar en los perjuicios que puedan causar, buscan ante todo configurar una profesión a su medida aunque esto represente una ruptura descarada y sin precedentes con la verdadera acepción de la misma. Es evidente en dónde se asientan las posturas que enarbolan al respecto los empresarios y ciertos periodistas españoles. Una burla social inaceptable que no merece tan siquiera ser contemplada.

\section{CONCLUSIÓN}

Resulta inaceptable -amén de una clara irresponsabilidad social- querer elevar al Periodismo a la categoría de profesión sin renunciar a su condición de oficio. $Y$ ésta es, tristemente, la gran invención ante la que hoy nos enfrentamos. Para los empresarios y cierto grupo de periodistas no parece tener mucha importancia la distinción entre estos dos estratos laborales, es más pretenden unificarlos en un derroche de ingenio inigualable. Bajo el rótulo de profesión se esconde, en cambio, el Periodismo de siempre. El que prolonga, en detrimento de la titulación académica específica, una educación artesanal en el mismo lugar de trabajo; el que diseña una singular colegiación voluntaria; el que considera que no puede haber un control del acceso y del ejercicio profesional más allá del meramente empresarial; el que no sólo no persigue sino que consagra el intrusismo; el que no tiene ningún reparo en compartir generosamente con empresarios y ciudadanos la elaboración, vigilancia y aplicación de su descafeinada deontología; el que adopta como suyas a las huérfanas formas informativas y comunicativas que circulan a través de los medios masivos de comunicación (salvo la denostada publicidad que parece tener progenitores propios); el que reclama la demostración de un número determinado de años de quehacer periodístico de forma habitual, principal y económicamente apta para asegurar el sustento vital... Condiciones todas ellas irrevocables para poder hablar de un Periodismo y un periodista profesional, que se limitan -y he aquí su máxima originalidad- a reeditar uno por uno los caracteres propios del oficio en clara contradicción con los requerimientos representativos de la profesión. Si el

\footnotetext{
${ }^{71}$ Aquellos que estén interesados en ampliar esta información pueden acudir a REAL RODRÍGUEZ, Elena: op. cit., tomo I, pp. 406-446. Próximamente, en el oo 4 de la revista Doxa Comunicación, saldrá publicado un artículo titulado "Profesión periodística y Unión Europea: hacia una unificación de la reglamentación dentro de la profesión", que es parte de la tesis doctoral anteriormente citada debidamente revisada y actualizada.
} 
Periodismo continúa hoy al igual que antaño tan lejos de la profesión no es porque no pueda o no esté capacitado para constituirse como tal, sino, más bien, porque no le dejan inconfesables intereses -ya externos ya internos al ámbito periodísticoque han impuesto su pervertida visión de la profesión con los más mezquinos y zafios engaños. El Periodismo-actividad, lejos de perecer herido por su inaceptable anacronismo, ha usurpado impunemente el lugar que le corresponde al Periodismoprofesión, del que sólo mantiene el fúlgido significante obviando por completo la esencia de su significado. De ahí mi afán por esclarecer los entresijos de esta controversia. Por este motivo mi obstinación en despertar la conciencia profesional de los periodistas.

\section{REFERENCIAS BIBLIOGRÁFICAS:}

ANECA: "Libro Blanco de las Titulaciones en Comunicación" en www.aneca.es y cccweb.uab.es/pr.aneca.comunicacion/aneca_comunicacion.htm

AZNAR, Hugo: Comunicación responsable, Ariel, Barcelona, 2005 (2丞 edición actualizada).

BENITO JAÉN, Ángel: La invención de la actualidad, Fondo de Cultura Económica, Madrid, 1995.

DESANTES GUANTER, José María: El futuro de los profesionales de la información, Ediciones Universidad San Sebastián, Santiago de Chile, 1992.

DE AGUINAGA, Enrique: Periodismo, profesión, Fragua, Madrid, 1980.

- "Periodismo colegiado", conferencia pronunciada en el Club Internacional de Prensa de Galicia, Santiago de Compostela, 6 de febrero de 1999.

DIEZHANDINO, María Pilar, BEZUNARTEA, Ofa y COCA, César: La elite de los periodistas, Servicio de Publicaciones de la Universidad del País Vasco, Bilbao, 1994.

ECOBAR ROCA, Guillermo: Estatuto de los periodistas, Tecnos, Madrid, 2002.

FAPE: "Comunicación institucional, una especialidad de la profesión informativa", dossier especial, en FAPE, no 30, abril-mayo 1998, pp. 32-33. (Sin firma)

o "Estatuto del Periodista" en Periodistas [Fape], revista de la Federación de Asociaciones de la Prensa de España, no 2, junio-agosto 2005, pp. 41-44. (Sin firma)

GALDÓN, Gabriel: La enseñanza del periodismo, CIMS, Barcelona, 1999.

HORTAL ALONSO, Augusto: Ética general de las profesiones, Desclée De Brouwer, Bilbao, 2002.

Proposición de Ley del "Estatuto del Periodista Profesional" en www.xornalistas.com/ pdf/PLEPP.pdf

REAL RODRÍGUEZ, Elena: Formación y ejercicio profesional del periodista en la España del siglo XXI dentro del marco de la Unión Europea (Tomos I y II), tesis doctoral, Universidad Complutense, Madrid, 2003. 
- "Un intento por clarificar los actos propios del ejercicio periodístico", en Estudios sobre el mensaje periodístico, no 11, 2005, Servicio de publicaciones Universidad Complutense, pp. 129-151.

- "Algunos interrogantes en torno a los estudios de Periodismo ante el nuevo Espacio Europeo de Educación Superior", en Cuadernos de Información y de Comunicación (CIC), no 10, 2005, Servicio de Publicaciones Universidad Complutense, pp. 267-284.

o "Profesión periodística y Unión Europea: hacia una unificación de la reglamentación dentro de la profesión", en Doxa Comunicación, № 4, 2006, Universidad San Pablo-CEU (en prensa).

SINOVA, Justino: "Garantías en el ejercicio profesional del periodismo", en Telos, no 49, marzo-mayo de 1997, p. 13.

- "Un error básico entre algunos aciertos", en Periodistas[Fape], revista de La Federación de Asociaciones de la Prensa de España, № 2, junio-agosto 2005, p. 40.

SORIA, Carlos: La crisis de identidad del periodista, Mitre, Madrid, 1989.

o "Los restos del naufragio", en Periodistas, no 35, julio 1990, pp. 12-24.

(Recibido el 20-02-06, aceptado el 16-05-06) 